\title{
The perspectives of traditional and modern medicine on the nature of hot and cold foods
}

\author{
Corresponding author: \\ Mehrab Dashtdar. Department \\ of Integrative Medicine, Dubai \\ Specialized Medical Center \& Medical \\ Research Lab, affiliated with Dubai \\ Medical College and Dubai Pharmacy \\ College, Dubai, United Arab Emirates. \\ Post Box 34395, Bur Dubai, \\ United Arab Emirates; \\ e-mail: dr.mehrab@gmail.com \\ Medical Research Journal 2022; \\ Volume 7, Number 1, 82-93 \\ DOI: 10.5603/MRJ.a2022.0001 \\ Copyright $\odot 2022$ Via Medica \\ ISSN 2451-2591 \\ e-ISSN 2451-4101
}

\begin{abstract}
A better understanding of traditional medicine requires a more accurate comprehension of the philosophy and culture in which traditional medicine is rooted. From the perspective of traditional Chinese medicine, the effects of foods on human health are inseparable from temperament, mind, body, and environmental factors. The links between these components may not be explained clearly in modern medicine [1]. This article aims to review perspective of traditional and modern medicine on the nature of hot-cold food, to explain more clear the concepts of traditional medicine in this subject, subsequently to promote its global applicability.

Key words: traditional medicine, four temperaments, nature of foods, hot \& cold
\end{abstract}

Med Res J 2022; 7 (1): 82-93

\section{Introduction}

The World Health Organization says that traditional medicine plays a very important role due to its affordability and availability in the health system and economy in Africa, Asia, and Latin America [2]. When reviewing alternative medicine, one of the first problem we face is how to define it, which is not yet fully understood, therefore, it is necessary to clarify some terms. It was believed that the development of modern medicine was going to make alternative medicine obsolete. Nevertheless, the failures and the limits of modern medicine have favored the development of alternative medicine [3].

We often forget that a quarter of modern medicines are derived from natural products, which were first used in traditional remedies. Westerners easily misunderstand the principles and practice of Chinese medicine due to numerous factors, such as philosophical, cultural, and linguistic and semantic differences in Chinese-English translation. So far, many books and articles have been written advocating or against traditional Chinese medicine, despite being experts in western medicine [4]. The books authored by Western specialists who had little knowledge of Chinese culture, language, and medical philosophy were superficial and most of the time misled readers. The second group of English books on Chinese medicine was written or translated from classical texts by authors who knew Chinese medicine well; however, unfortunately, they did not have enough linguistic ability to present the material in a way understandable to the western reader. Some books even described the medical practice in China as superstitious and metaphysical or said that it was based on antiquated socio-political systems [5]. There is no doubt that a medical practice that has been successful for thousands of years by a great civilization must have something useful to teach us. According to the principles of Western medicine, the knowledge of traditional medicine has been misinterpreted or misunderstood. Traditional Chinese medicine has its own phrases and words, which have completely different meanings if not studied in the context. Finding the roots of these words 
or phrases makes it possible to understand accurately traditional Chinese medicine.

\section{Differences of view between traditional Chinese medicine and western medicine}

The basic assumptions behind the treatment, biomedical research, and patient care can have far-reaching implications for patient health. Adherence to a procedure may limit the possible options that physicians and researchers can consider. Particularly, the controversy between the utilization of reductionism or holism has influenced conventional ways of thinking in medicine and created new opportunities to boost healthcare. Man has two different methods of studying objects: "reductionism" and "holism." The "reduction theory" method is to decompose the system into simpler components, study its properties, and then use formal logic to infer its overall state. Holistic therapy is an unconventional approach to medicine, which is based on the principles of holism (interested in objects in comprehensiveness) and the "wholeness of the human being" in the physical, emotional, mental, spiritual, environmental, and socio-cultural sense. It is a matter of considering the patient as a person and not a simple patient. Reductionism tends to be the dominant approach in western medicine. This has been proven both empirically and anecdotally; physicians typically tend to ask questions that get to the root cause of what is causing the patient pain or discomfort. Then, once this cause is isolated, treatment and a care plan are prescribed based on tackling this cause alone. Chinese medicine has a holistic approach in which different human functions must be coordinated and balanced, so adjusting this balance is the basis for treating diseases [6]. Western medicine focuses on entities, while Chinese medicine focuses on relationships. The theory of yin and yang and the five elements of traditional Chinese medicine are used to describe the basic form of the complex system of the human body. They are two opposites of a whole, which cannot exist alone and want to transform each other [7]. From this perspective, research in this field becomes a complex science. It is a pity that many people regard these things as "fraught with pseudoscience" [8]. The advantage of western medicine lies in the support it has had from modern science research since the industrial revolution. Western medicine is based on treatments, which have obtained scientific validation, through clinical trials, or because they benefit from a strong professional consensus obtained with the agreement and experience of the majority of professionals of the discipline concerned. In the vast majority of cases, traditional Chinese medicine practices have not been the subject of scientific or clinical studies showing their modalities of action, their effects, their effectiveness, as well as their non-dangerousness and stays in a primitive state of experience. However, these experiences have been proved by human civilization for thousands of years [9].

This article aims to review perspective of traditional and modern medicine on the nature of hot-cold food to promote its global applicability. In this article, we will first review the four temperaments and then evaluate the views of traditional and western medicine on this matter, respectively.

\section{Four temperaments}

Ancient Greeks believed that everything that exists in nature is made up of four elements (air, earth, fire, and water), and a person's personality or temperament depends on the strength of various fluids or "humor" in a person's body [10]. According to the Greek doctor Hippocrates (c. 460-c. 370 BC) and (later) Galen, there are four main body fluids, each of which is responsible for a specific personality pattern (and disease susceptibility). One of the body fluids is blood, and too much blood is thought to produce a very cheerful ("optimistic") temperament. According to Hippocrates and the subsequent tradition, melancholy was caused by an excess of black bile, hence the name, which means "black bile," from the ancient Greek (melas), "dark, black" and (kholé), "bile." A person whose constitution tended to a preponderance of black bile would have a "melancholic" predisposition. Excessive humor called Yellow Bile, or the Choleric humor is believed to be responsible for the temperament of anger ("bile"). The remaining excess humor, the phlegm, is seen as the basis of a calm ("phlegm “) temperament. According to Hippocrates, differences among individuals are linked to the predominance of one of these four temperaments [11].

\section{Manifestation of four temperaments}

\section{Hot and dry temperament (Yellow Bile, or the Choleric humor)}

In choleric humor person, faces and sclera tend to be yellow, mouths and noses are dry, and their tongues become dry, rough, and sometimes bitter. These people are very thirsty but have no appetite. They are thin and sharp-minded. They cannot be deceived easily. They have short and shallow sleep. They have a bad temper and easy to get angry. Their skin is hot, dry, and dull with sunken eyes. They feel warm in extremities and enjoy the cool air but are bothered in hot weather. Their first-morning urine is dark and sometimes with a burn- 
ing sensation. Their warmth and dryness intensify in summer. Always fast in chewing, walking, and talking, and usually in rush. People with biliary temperament have most health problems at a young age, and most of these problems occur especially in the summer [12].

\section{Warm and wet temperament (blood)}

The sanguine temperament has historically been considered as the hot and humid temperament because of an excess of blood, marked by a warm and sanguine temperament (enthusiastic, active, and social). This temperament is explained by a fast and balanced nervous system that allows people to have a high degree of sensitivity, a high level of activity and concentration, flexibility in the face of changes, among others. Their face is red, with a sturdy structure, feeling heavy, especially behind the eyes, head and temples and extremities. They are usually dull and have a heavy sleep that intensifies in spring. Frequent yawning, stretching the arms around are among their habits. These people are usually strong, good-natured, talkative, and funny, and inspire others. They are brave and obedient, but they do not understand new content well and forget soon. Nasal and gum bleeding happen easily in these people. The skin becomes itchy at the site of cupping. These symptoms are more common in spring [13].

\section{Cold and dry temperament (melancholy)}

Melancholy temperament have a lean and bony Physique. Their faces are dark, and their skin is dry and without freshness. Depressive people generally show withdrawn behavior, they are not sociable, but a careful observation. They are very sensitive, shy, sentimental, slow to act, indecisive, and introverted; they think and worry a lot about what is going on around them. They have gloomy dreams with disturbance in sleeping and poor appetite, abulia, and irritability. More poets and artists can be found among these people due to the speed of thought, but if they do not improve their lifestyle and nutrition, they will suffer from serious psychological problems. Heartburn and stinging, cramps in the muscles of the back of the legs. False appetite and cannibalism, hair loss, and dark spots on the skin are common among them. These people are in better balance in the spring and their illnesses get worse in the fall [14]. The association of "globus hystericus" or the sensation of a lump or foreign body in the throat is common in these people [15].

\section{Cold and wet temperament (phlegm)}

Phlegmatic temperaments have light skin color and blond hair [16]. Their skin is cold, soft, and clear, but sometimes the skin around the eyes and under the throat wrinkles due to moisture. Excessive saliva, little thirst, soft flesh, laziness, acid reflux are other symptoms of phlegm. The movements of these people are slow so that others get tired of them. They talk quietly and usually fall behind in walking and get tired quickly. Milk and dairy products, wheat flour and cold foods, and cold drinks, creamy rich foods are contraindicated in this temperament. [17]. Symptoms of drowsiness, sluggishness, memory loss, pale morning urine, and a soft tongue. They have a good natured, kind, nurturing, compassionate, sympathetic Personality. In winter, phlegm diseases get worse [18].

Table 1. Relations of four temperaments with seasons, four elements, and climate and psychological trends

\begin{tabular}{lcccc}
\hline Four temperament & $\begin{array}{c}\text { Nervous } \\
\text { (melancholic) }\end{array}$ & $\begin{array}{c}\text { Bilious } \\
\text { (choleric) }\end{array}$ & $\begin{array}{c}\text { Sanguineous } \\
\text { (blood) }\end{array}$ & $\begin{array}{c}\text { Lymphatic } \\
\text { (phlegm) }\end{array}$ \\
\hline Mood stability & Unchangeable & Changeable & Changeable & Unchangeable \\
Qualities & Dry + cold & Dry + hot & Moist + hot & Moist + cold \\
Humor & Black bile & Yellow bile & Blood & Phlegm \\
Element & Earth & Fire & Air & Water \\
Seasons & Autumn & Summer & Spring & Winter \\
Generated in & Brain & Liver & Heart & Stomach \\
Psychological trend & Depressed & Excitable & Playful & Reasonable principled \\
& Anxious & Exhibitionist & Easygoing & Controlled persistent \\
& Worried & Egocentric & Sociable & Carefree \\
Unhappy & Histrionic & Hopeful & \\
Suspicious & Impulsive & Contented & \\
Serious & Thoughtful & & Weak emotion & \\
\hline
\end{tabular}

Developed from Galen's theory of the four temperaments. Kant proposed trait words to describe each temperament. Wundt later suggested the arrangement of the traits in two major categories 
Table 2. Most famous hot (Hyper Yang) foods in nature

\begin{tabular}{|c|c|c|c|c|c|c|c|}
\hline $\begin{array}{l}\text { Condiments } \\
\text { \& spices }\end{array}$ & $\begin{array}{c}\text { Animal } \\
\text { products }\end{array}$ & Sea foods & Fruit & $\begin{array}{c}\text { Nuts, seeds } \\
\& \text { oil }\end{array}$ & Vegetables & Beverage & Beans \\
\hline Anise & Camel milk & Eel & Apricot & Chestnut & Asparagus & Black tea & Chickpea \\
\hline Cinnamon & Cottage cheese & Herring & Cherry & Coconut & Basil & Coffee & Lentils \\
\hline Coriander & Deer meat & Sardines & Dates & Cereals & Chives & Red wine & Sesame \\
\hline Cumin & Duck & Sea scallops & Durian & Canola oil & Coriander & Vinegar & \\
\hline Cloves & Goat's milk & Shrimp & Guava & Caraway seed & Dill & & \\
\hline Curry powder & Lamb & Salmon & Jackfruit & Fennel seed & Garlic & & \\
\hline Garlic & Mutton & Tuna & Jujube & Mustard & Leeks & & \\
\hline Ginger & Offal & & Kumquat & Pistachio & Onions & & \\
\hline Nutmeg & Silkie chicken & & Long Yan & Pine nut & Oyster mushroom & & \\
\hline Peppers & Sheep's milk & & Lychee & Sunflower & Pumpkin & & \\
\hline Turmeric & Veal & & Mango & Walnut & Rosemary & & \\
\hline \multirow[t]{2}{*}{ Saffron } & & & Peach & & Shallots & & \\
\hline & & & $\begin{array}{c}\text { Sweat } \\
\text { Pomegranate }\end{array}$ & & & & \\
\hline
\end{tabular}

\section{Traditional vs. western medicine in nutritional therapy}

Nutritional therapy is the scientific application of how food, nutrients, and lifestyle can affect our well-being. Using in-depth knowledge of biochemistry, nutritional therapists seek to recognize external factors (lifestyle, diet, and environment) that can negatively influence our health and strive to correct these imbalances through healthy diet plans and, where appropriate, supplementation [19]. Traditional Chinese medicine believes that everyone's physique, temperament, and health status are different and change with age. Diet and nutrition can guide the body to restore balance by avoiding foods that exacerbate imbalances. This concept is closely related to modern medicine, where most cancers and other degenerative diseases are caused by improper diet and nutritional deficiencies. Foods, like human nature, are divided into four categories cold, cool, warm, and hot according to their effects on the body [20]. Foods that can increase body heat, promote circulation, and boost body energy are warm; and those that can calm the blood, remove toxins and reduce calories, on the contrary, are cold foods [21, 22]. [Table 2-4]

\section{Traditional Chinese medicine perspective views on hot or cold foods and temperament}

Traditional Chinese medicine pays attention to syndrome differentiation and treatment. Before prescribing the medicine or foods, it is necessary to identify the patient's nature and to use suitable diets or medicines for people of different constitutions and diseases in order to avoid harm and maximize efficacy [23].

Natures of foods: The dietary regimen must first talk about "nature (in Chinese "Xing"), which refers to the different properties of food such as cold, cold, warm, and hot, which are called "four natures" or "four qi " in Chinese medicine. The nature of food is defined by the thermal and physiological effect that it will produce on the organism, after having been absorbed. This effect has nothing to do with the temperature of the food. For example, foods of hot nature will raise the temperature in certain areas of the body and strengthen the energy of certain organs; the body increases its activity, it is warmed up and stimulated, its metabolism is activated. As for foods of a cold or fresh nature, they will rather cool the body and slow down the circulation of blood and energy. The way food is cooked can change this nature (grilling, maceration, infusion, etc.). For example, the longer the food is cooked over high heat, the hotter in nature it will be. Depending on their nature, foods can throw us off balance and cause disease, but they can also be used to restore harmony [24]. A person with the characteristics of tiredness, pale tongue, and complexion, poor digestion, and abundant urine will benefit from the properties of warm and hot foods (which increase internal activity) and should avoid cold or fresh foods. The reverse will be true for a person who is always hot or thirsty, with red eyes and complexion, low volume and dark urine, rapid heartbeat, etc.

Food is an important factor in daily life of human being, which should have a proper diet with adequate calorie intake, nutritious meals, salads, fruits, and 
Table 3. Most famous cold (Hyper YIN) foods in nature

\begin{tabular}{|c|c|c|c|}
\hline Animal products & Fruit & Vegetables & $\begin{array}{l}\text { Beans/nuts, seeds } \\
\& \text { and their products }\end{array}$ \\
\hline Clams & Apple & Bamboo shoot & Barley \\
\hline Cow milk & Avocado & Bitter gourd & Buckwheat \\
\hline Duck & Aegle marmelos & Celery & Soy sauce \\
\hline Horse & Banana & Cucumber & Corn \\
\hline Lard oil & Blueberry & Chinese cabbage & Millet \\
\hline Lobster & Carambola & Eggplant & Mung bean \\
\hline Meat, buffalo & Cantaloupe & Green tea & Tofu \\
\hline Oyster & Dragon fruit & Lettuce & Soybean germ \\
\hline Octopus & Grapefruit & Mint & Wheat \\
\hline Rabbit & Hawthorns & Mushroom & Wheat bran \\
\hline River crab & kiwi & Radish & \\
\hline Shellfish & Lemon & Seaweed & \\
\hline Sheep's hoof & Loquat & Squash & \\
\hline Sea urchin & Melons & Spinach & \\
\hline Snail & Mangosteen & Tomatoes & \\
\hline Turkey & Mandarin orange & Turnip/beetroot & \\
\hline \multirow[t]{9}{*}{ Yogurt } & Orange & White tea & \\
\hline & Pomelo & Winter melon & \\
\hline & Pineapple & & \\
\hline & Persimmon & & \\
\hline & Pear & & \\
\hline & Sour pomegranate & & \\
\hline & Strawberry & & \\
\hline & Star fruit & & \\
\hline & Watermelon & & \\
\hline
\end{tabular}

Table 4. Most famous neutral food

\begin{tabular}{lllllll}
\hline Animal products & Green vegetables & Root vegetables & Tubers & Oilseeds & Fruit & Cereals \\
\hline Beef liver & Broad bean & Potato & Yam & Almond & Fig & Adzuki bean \\
Carp & Black mushroom & Taro & & Peanut & Grapes & Brown rice \\
Cheeses & Cabbage & Sweet potato & & Sunflower & Plum & Cowpea \\
Egg yolk & Olive & & Sesame & Flour \\
Honey & Peanut & & & Oats \\
Lean fish & Rice & & & Pasta \\
Pork heart & Shiitake Mushrooms & & & Rye \\
Pigeon & White mushrooms & & & White bean \\
Pork & & & & \\
Quail & & & & \\
Sturgeon & & & & \\
Tripe & & & & \\
\hline
\end{tabular}


Table 5. The warm nature of food also meets its opposite needs. The hot nature is used to reheat, but also to disperse the cold and to warm the internal organ. The cold nature of a food is used to cool, but also to suppress heat, disperse fire

\begin{tabular}{lll}
\hline Hot food & Neutral & Cold \\
- Add more heat & - Moderate the action of other products & - Slow down the metabolism \\
- Disperse the cold & - Ensure balance & - Cool and refresh significantly \\
- Warm the internal organs & - Strengthen the whole organism & - Clarify the heat \\
- Prevent Fainting & & - Purge, disperse the fire \\
- Unclog the vessels & & - Refresh the blood \\
- Strengthen Yang and move the Qi & - Eliminate the toxin \\
- Protect the body from external influences & & - Nourish the YIN \\
\hline
\end{tabular}

grains. These foods contain nutrients, vitamins, minerals, enzymes, and other compounds that can help our body to function normally. They have a different nature that can improve a person's body and mind by affecting their mood [25]. Generally, foods of plant origin will be rather cool or cold, while foods of animal origin (meat, milk, eggs) will be warm or hot. The meat of animals with strong muscles, unlike inactive animals, has more energy. Likewise, if the food comes from an aquatic environment (rivers, lakes, seas), it is of a colder nature than that which comes from the earth [26].

\section{Each nature of food has a privileged function}

In Chinese medicine, food and medicine are of the same origin. In other words, there is no clear distinction between food and medicine. The most common foods we eat can be also medicine if used properly. Chinese medicine emphasizes that food and medicine are closely related, and there is no difference.

\section{The Yin and Yang of food}

The balance of Yin and Yang is the foundation of vitality. This balance means people are healthy and energetic; people who are out of balance will suffer from illness, premature aging, and even death, so the aim of the traditional Chinese medicine diet is to harmonize the "mutually attractive opposites," the Yin and Yang. Health, well-being, and mental balance are strengthened when there is a harmonious balance between these, and the life energy Qi can flow undisturbed [27]. To achieve a specified effect or to strengthen or downregulate a certain organ, of human body, should increase or reduce the proportion of the corresponding food, and the nature and energy of the food should be taken into account. Depending on the season, weather, or physical and mental needs of individuals can consume the warming, cooling, or refreshing foods from the TCM diet. Foods are classified according to their Yin-Yang nature, their flavor, their action on the overall thermodynamic in the body, and how they circulate energy into various internal organs. Yang-type foods raise energy (e.g., alcohol), while Yin-type foods lower energy. Depending on the nature of the yin or yang, foods can internalize or externalize their energy [28]. In traditional Chinese medicine, cold and heat syndrome is one of the special contents of the eight Principles of Diagnosis (in Chinese Bian Zheng), which include yin and yang, external and internal, cold and heat, deficiency, and excess. Syndrome differentiation in traditional Chines medicine is a comprehensive analysis of data obtained through four diagnostic methods (inspection, listening and smelling, inquiring, and palpation) through analysis and synthesis, to distinguish the etiology, nature, location of the disease, and the relationship between evil and goodness, and to generalize and diagnose it as a syndrome of a certain nature [29,30]. The characteristic of the syndrome differentiation with the eight principles is to grasp the integrity, certainty, and correlation of the occurrence and development of the disease. Cold and heat are the two most basic guidelines for distinguishing the cause of disease. In traditional Chinese medicine, syndrome refers to a certain stage of the occurrence and evolution of a disease and the reflection on the nature of the specific internal and external environment of the individual patient at that time. Therefore, the syndrome divulges the essence of the disease more comprehensively, more profoundly, and more accurately than the symptoms.

\section{Cold}

In traditional Chinese medicine, liu Qi or the six climatic energies, "the so-called six evils: wind, cold, heat, wet, dry, and fire", which found in nature in a normal state, they could become a source of disease if they are out of balance. Imbalanced means too strong or too weak, not arriving at the right time, or staying too long, and the cold is one of these six pathogenic causes of disease. The pathogenic factors of cold are divided into internal cold and external cold. The cold syndrome is a syndrome manifested when a person is feeling cold or experiencing insufficient yang Qi in the body. The cold hurts the Yang, especially the (Yang Qi). When the Yin is prosperous, it hurts the Yang, the person then suffers 
from chilliness, and his limbs are cold. Extra cold is often associated with chills, pain, shortness of breath, pale mouth but not thirst, cold limbs, sputum, salivation, and tears, clear and long urine, loose stools; pale complexion, pale tongue with white and moist fur, tight or late pulse [31]. The TCM considers that cold can attack the body, enter the meridians and cause external diseases when exposed to cold temperatures or ingested too many cold-type foods. We then speak of external cold as opposed to internal cold, which is created inside the body without being directly exposed to the cold. In this case, it is the slowing down of the metabolism or the reduction in the activity of the organs that generate the symptoms of the cold type. The spleen/pancreas, the kidney, and the heart are most often affected by this lack of vitality, causing symptoms such as decreased appetite, bloating, fatigue, weakness in the limbs, loose stools, clear and abundant urine, edema, impotence, low libido, etc. Symptoms of an internal cold usually appear more slowly than those of an external cold.

\section{Manifestation of the cold syndrome}

The main symptoms of the cold syndrome are coldness and pain in the hands, feet, and lower abdomen, which are relieved by warmth, intolerance to cold, and preference for warmth. Cold and blueish-purple hands and feet, delayed menstruation, dark purple menstrual flow with clots, dysmenorrhea, pale tongue, white coating, slow deep unsmooth pulse, abdominal pain, borborygmus, diarrhea, vomit, pale tongue with white coating or spasm of four limbs, extremely cold limbs, minute pulse are other signs of aversion to cold [32, 33]. In modern medicine, vascular diseases are any abnormal condition of the blood vessels that cause poor circulation. It is a common problem caused by a number of conditions. The most common vascular diseases are stroke, deep vein thrombosis (DVT), peripheral artery disease (PAD), abdominal aortic aneurysm (AAA), coronary artery disease (CAD) and carotid artery disease, arteriovenous malformation (AVM), critical limb-threatening ischemia (CLTI), pulmonary embolism (blood clots), chronic venous insufficiency (CVI), Raynaud's disease, aneurysm, and varicose veins. The reduced blood flow can cause uncomfortable symptoms, such as muscle cramps, numbness pain, cold hands or feet, and digestive problems. Poor circulation is often treated with medications, eating certain foods to improve blood flow. Since the consumption of hot foods increases blood circulation, so in addition to allopathic medicines, most spices can be used to treat poor circulation. [34]

\section{The heat}

Heat syndrome is the syndrome manifested when feeling the heat evil or the deficiency of Yang Qi and
Sheng Yin liquid. Aversion to heat is often associated with acute onset, relatively short duration, persistent high fever, thirst for cold drinks, red face, fullness and distending pain in the abdomen, constipation, urinary difficulty or yellow urine, irritability, yellow and thick phlegm; the tongue is red, with yellow fur, rapid pulse. Traditional Chinese Medicine (TCM) associates Heat with Yang energy, which has dynamic characteristics such as growth, stimulation, warming, and evaporation. Heat can become a pathogenic factor if it is in excess. It will then tend to over-activate our internal metabolism (exaggerated activity of the organs, the feeling of being hot, agitation of the mind, etc.) and to evaporate our liquids (causing thirst, dry skin, etc.). The TCM suggests that the attacks by Heat can come from outside by exposure to an abnormally hot temperature (exterior heat syndrome), for example, mild weather in winter or a heatwave in summer; it is then external heat. Heat can also come from inside the body without direct exposure to heat (interior heat syndrome). We then notice an increase in the body's metabolism and a great stimulation of the activity of the organs. In addition, too much heat unduly stimulates Yang to the detriment of Yin. The latter is no longer able to perform its functions of nutrition and appeasement, so there may be an onset of illness. Excessive heat appears in the form of dizziness, headache, flushing, tinnitus, and sores in the mouth. In addition, it can damage blood vessels (bleeding from the gums, nose), create dryness (constipation, thirst, dark, and scarce urine), and cause mental agitation (nervousness, irritability) and insomnia. The stomach, heart, and liver are the organs most often affected by this extreme fire [35].

\section{Characteristics of hot syndromes}

Red eyes, coma, and delirium, mental restlessness or mania, stiff neck, mouth ulcerations, swollen gums, dryness of mouth with no desire to drink, low and dark urine, dry stool, red tongue are characteristics of heat syndromes. It can also manifest itself as hemoptysis, hematemesis, bleeding from eyes, ears, nose, mouth, or subcutaneous tissues, hematuria, hematochezia, early menstrual cycle, or disruption in the menstrual rhythm, menorrhagia, mild fever, and crimson tongue, rapid or slippery pulse [36].

\section{Modern medicine views on hot or cold foods and temperament}

\section{Some cold foods containing GABA $(\gamma$-aminobutyric acid)}

$\gamma$-aminobutyric acid (GABA) is a non-protein amino acid whose main electrophysiological effect is the inhibition of membrane action potentials. It reduces the 
activity of the central nervous system and blocks certain signals from the brain. Without gamma-Aminobutyric acid, the brain would be "on" all the time. GABA is necessary to produce a calming effect that slows and reduces the heart rate and blood pressure, in addition to promoting relaxation before sleep. Normal stressors respond well to GABA. Fish and shellfish, beans, sprouted whole grains (especially brown rice), potatoes, tomatoes, seaweed, berries, white tea, mushrooms all contain GABA ( $\gamma$-aminobutyric acid) [37].

Hashimoto's thyroiditis is a common autoimmune disorder. The most common symptoms can be anxiety, negative mood, depression, dry skin, sensitivity to cold, puffy eyes, muscle cramps and fatigue, deep voice, constipation, slow thinking, and poor memory [38]. Clinical manifestations of the disease are primarily defined by having low thyroid hormones; hence, it is treated through hormone replacement therapy, which usually consists of levothyroxine (LT4). Selenium could reduce antibody levels and result in a decreased dose of LT4 and can deliver other positive effects (e.g. on mood and health-related quality of life) [39].

\section{Some hot foods, which contain selenium}

Selenium is a vital trace element necessary for the human body; sufficient levels of this element are required in the diet to maintain health and reproduction. Most selenium exists in red blood cells as a component of glutathione peroxidase. Intracellularly, it has an antioxidant effect, as it allows the body to produce glutathione peroxidase, this enzyme works together with vitamin $\mathrm{E}$ to protect cell membranes against oxidation caused by free radicals. [40, 41]. Foods that are high in selenium are warmer and cold foods are generally selenium-free.

\section{Some cold foods containing tryptophan}

5-HTP is an amino acid that our body produces from tryptophan, which is found in protein foods (meat, poultry, fish, dairy products, legumes, and nuts). Once absorbed, 5-HTP crosses the blood-brain barrier and transforms in the brain into serotonin, a neurotransmitter that plays an essential role in regulating mood (as a tranquilizer), anxiety, appetite, and sleep [42].

Serotonin deficiency. Too low serotonin levels promote impulsivity, irritability, aggressiveness, even, in extreme cases, suicidal tendencies [43]. A drop in serotonin level in the brain promotes snacking by compulsions, especially at the end of the day; it creates a craving for sweet foods [44]. In this sense, it is necessary to take into account that to produce serotonin the body needs a substance called tryptophan. Tryptophan is an essential amino acid which cannot be synthesized by the body or which is synthesized at an insufficient rate, and must therefore be provided by the diet, primarily from animal or plant based protein sources. . Eggs, pasta, rice, dairy products, cereals, chicken, turkey, bananas, legumes, among others. However, serotonin levels also can increase through regular exercise or relaxation techniques such as yoga. In the human body, in order to produce serotonin optimally, the body needs valuable vitamin $\mathrm{B} 6$ in addition to zinc and magnesium [45].

\section{Some hot foods containing dopamine}

Dopamine is the main neurotransmitter involved in the reward circuit in the brain, but other molecules are also involved: GABA, norepinephrine, serotonin. The addiction to drugs is linked to a disorder of the reward circuit because drugs, such as cocaine, morphine, and heroin, stimulate the release of dopamine. Drugs produce a feeling of satisfaction, which leads to addiction in addicts. Dopamine enhances the sense of pleasure, thereby activating the reward/reinforcement system. This system of "rewards" is essential for survival because it provides the motivation necessary for carrying out appropriate actions or behaviors (search for food, reproduction, avoidance of dangers, etc.) allowing the individual and the species to be preserved. Dopamine, GABA, norepinephrine, serotonin are also involved in certain abstract pleasures, such as listening to music. They also enable muscle movement, tissue growth, the functioning of the immune system, and the secretion of growth hormones. Dopaminergic networks are linked to motivation, exploration, curiosity, the search for pleasure and happiness [46-50].

Dopamine is produced in dopaminergic neurons in the ventral tegmental area (VTA) of the midbrain, the substantia nigra pars compacta, and the arcuate nucleus of the hypothalamus. Low levels of dopamine are linked to the decrease in the activity of dopaminergic neurons and lead to a decrease in spontaneous movement, muscle stiffness, and tremors (Parkinson's). They also lead to a decrease in motor activity, reduced motivation, and melancholy or depression [51]. When there is a dopamine deficit in the brain, movement can become delayed and disordered. On the other hand, if there is an excess of dopamine, the brain causes the body to perform unnecessary movements, such as repetitive tics. Dopamine levels are generally well regulated by the body, but diet and lifestyle changes can regulate these levels naturally. A balanced diet that contains adequate protein, vitamins and minerals, probiotics, and a moderate amount of saturated fat can help the body to produce dopamine. People with dopamine deficiency diseases, such as Parkinson's disease, increase their dopamine levels by eating dopamine-rich food sources, such as fava beans or velvet beans, also 
known as Mucuna pruriens, duck, eggs, and certain fresh cheeses (cottage cheese) [52].

\section{Some hot foods containing nutrients induce noradrenaline}

Noradrenaline regulates the hormones that manage fertility, libido, appetite, metabolism, and it modulates attention and learning, in particular, through reward signals [53].

Deficiency. The decrease or disturbance of the synthesis of noradrenaline can cause psychological disorders (withdrawal into oneself, detachment, demotivation, depression) and a decrease in libido [54]. Iron is also part of the composition of enzymes, which are involved in metabolic reactions such as the synthesis of DNA or certain neurotransmitters such as dopamine and adrenaline. Same foods as dopamine, associated with co-factors (iron, caffeine, etc.) [55].

\section{Coffee: stimulant, antidepressant}

The stimulating effect of coffee stems largely from the way it acts on adenosine receptors in the neuronal membrane. Adenosine is a neuromodulator of the central nervous system that has specific receptors. When adenosine binds to its receptors, neuronal activity slows down and creates a feeling of drowsiness. Adenosine, therefore, facilitates sleep and dilates blood vessels, possibly to ensure good oxygenation during sleep. Stimulants such as caffeine or theophylline act as antagonists at the level of adenosine receptors, preventing adenosine from lodging there and playing its role of "the brake" and leading to the acceleration of neuronal activity. The activation of many neural circuits by caffeine also makes the pituitary secrete hormones that cause the adrenal glands to produce more adrenaline, which is a stress hormone. Adrenaline is a "fight or flight hormone," so it increases the level of attention and gives the nervous system extra energy. This is exactly the effect that coffee drinkers are looking for. In general, each cup of coffee has some stimulating effect. This effect can last for several hours, and adrenaline and other stress markers can stay high until the end of the day, even after drinking a little coffee in the morning [56].

\section{Some hot foods containing nutrients induced acetylcholine}

Acetylcholine is the major neurotransmitter of bulbospinal neurons in the parasympathetic nervous system. Acetylcholine is related to learning and the formation of memory [57]. Deficiency in the brain is partly responsible for the symptoms of Alzheimer's disease [58].
Rosmarinus officinalis, better known as rosemary oil, is a plant whose properties from aromatherapy (inhaled essential oils) attribute specific therapeutics, such as antioxidant, antiviral, antidepressant, diuretic, anti-inflammatory, gastrointestinal, among others. $\alpha$-Pinene, 1,8-cineole, camphor, and borneol are usually the main rosemary oil constituents, which inhibits acetylcholinesterase activity in vitro. This enzyme catalyzes the hydrolysis of acetylcholine at the cholinergic terminals, thus, in some dementias, where this neurotransmitter is decreased, as in Alzheimer's Syndrome, the inhibition of the catalytic activity of this enzyme could be an alternative route to control this disease. This spice even can improve $\operatorname{mood}[59,60]$.

Thermogenesis foods. Thermogenesis naturally promotes the production of digestive enzymes that metabolize nutrients and eliminate waste and toxins. They also improve protein digestibility and prevent hypoglycemia - sudden cravings for sweets - which are very common in winter.

The Glycemic Index represents the ability of a carbohydrate food to change glycemia (the blood glucose level) within 2 hours after ingestion. A relatively new concept in nutrition, the glycemic load complements the glycemic index well. While the glycemic index only gives a measure of the quality of carbohydrates, the glycemic load also considers the actual amount of those carbohydrates in a normal serving. The reference food is white bread or glucose with a glycemic index of 100. Other foods are classified according to their glycemic index: low (less than 55), medium (55 to 70), or high (more than 70). Based on the compositional structure of vegetables and fruits such as cucumbers, raw celeriac, asparagus, apple, spinach, which belong to the group of cold foods, it can be said that these foods have a low glycemic index and a high percentage of fiber. In other words, they are low in calories and have the advantage of promoting digestion and the feeling of fullness. They, therefore, make it possible to reduce the daily caloric intake. A diet composed of these foods requires more energy to be digested and metabolized than the energy supplied by the food. Its thermal effect - the caloric "cost" to digest these foods - would be greater than the energy contained in the food. Physical effort, the sun, strong emotions, or even illness can raise the internal heat of the body and thus raise the body temperature [61-64].

Glycemic load. The glycemic index only indicates how quickly carbohydrates from a portion of food are absorbed into the bloodstream. It does not give information on the number of carbohydrates in the food, which is also important. The glycemic load includes the glycemic index and the number of carbohydrates 
in a portion of food. Foods, such as carrots, bananas, watermelon, or whole wheat bread, can have a high glycemic index while containing few carbohydrates, and therefore, have a low glycemic load. Such foods have little effect on the blood sugar level. The glycemic load is associated with how consumption of foods affects blood sugar level, but the glycemic index is not [65]. Glycemic index also takes into account the "anti-glycemic" effect of dietary fiber in foods. Therefore, even though watermelon has a very high glycemic index [66], its glycemic load for a normal $150 \mathrm{~g}$ serving is only five. On the other hand, the glycemic load of refined food, such as white rice, can exceed 25 for a $150 \mathrm{~g}$ serving. A single serving of white rice, therefore, provides the same glycemic load as five portions of watermelon. Most foods with a hot nature have a high glycemic index and glycemic load, and vice versa, in foods with cold nature, these two are low. Quantity and type of carbohydrates ingested, presence of other nutrients, gastric emptying rate, speed of digestion, and intestinal absorption of carbohydrates, hormonal factors (insulin, glucagon, and intestinal hormones), and the reaction of the liver influence the amplitude and duration of postprandial hyperglycemia. Regardless of the mechanism that delays gastric emptying, this delay is the most likely explanation for the flattening of the glucose response after a fiber-rich diet [67-68].

\section{Physiology of spicy foods}

Raw and cooked hot peppers such as cayenne pepper, jalapeno, and habanero can naturally speed up metabolism. A study by the Federation of American Societies for Experimental Biology also credits hot peppers with reducing appetite cravings due to the rich capsaicin they contain. The capsaicin compound naturally speeds up both blood circulation and metabolic rate, which is why one sweats when one eats hot wings or nachos seasoned with exceptionally hot peppers.

Pungent is the burning sensation in the mouth every time we ingest a spicy ingredient, which is perceived through the nociceptors (or pain receptor nerve endings) and not through the taste buds. Chewing these foods releases molecules, such as capsaicin (hot peppers), piperine (1-piperoyl piperidine) in black pepper, and Allicin (allyl 2-propenethiosulfinate or dially I thiosulfinate) in raw garlic and onion), among others, which chemically activate these free nerve endings located on the tongue. Therefore, it could be stated that spiciness is not a flavor but rather a sensation of pain to which the human body reacts by emitting doses of endorphin and serotonin, which can finally cause a sensation of pleasure $[69,70]$.

\section{Acknowledgments: I would like to express my special appreciation and thanks to Prof. Dr. Saeed}

Ahmed Khan, Dean, Dubai Pharmacy College, for continuous friendly support. I warmly thank all the authors for their collaboration and for their invaluable help, patience, and their proofreading and corrections. Above all, a big thank you to the Editorin-Chief: Prof. dr. hab. n. med. Jacek Kubica and the journal's scientific committee for allowing this issue to appear. A special thanks to my family. Words cannot express how grateful I am to them.

\section{Conflict of interests: None.}

\section{Funding: None.}

\section{References}

1. Nordström $\mathrm{K}$, Coff $\mathrm{C}$, Jönsson $\mathrm{H}$, et al. Food and health: individual cultural, or scientific matters? Genes Nutr. 2013; 8(4): 357-363, doi: 10.1007/s12263-013-0336-8, indexed in Pubmed: 23494484.

2. World Health Organization. ( 2013) . WHO traditional medicine strategy. https://apps.who.int/iris/handle/10665/92455.

3. Yuan $\mathrm{H}, \mathrm{Ma} \mathrm{Q}$, Ye Li, et al. The traditional medicine and modern medicine from natural products. Molecules. 2016; 21(5), doi: 10.3390/molecules21050559, indexed in Pubmed: 27136524.

4. Zhang, N. and Dong, M. (2020) Translation Strategies of Traditional Chinese Medicine Terms from the Perspective of Cross-Culture Communication. Open Access Library Journal, 7, 1-7. doi 10.4236/oalib.1106828

5. Hongjun Z. Chinese Versus Western Medicine: a history of their relations in the twentieth century. East Asian Science, Technology, and Medicine. 1991; 10(1): 21-37, doi: 10.1163/26669323-01001002.

6. Paterson C, Britten N. Acupuncture as a complex intervention: A holistic model. The Journal of Alternative and Complementary Medicine. 2004; 10(5): 791-801, doi: 10.1089/acm.2004.10.791.

7. Lu AP, Jia HW, Xiao C, et al. Theory of traditional Chinese medicine and therapeutic method of diseases. World J Gastroenterol. 2004 10(13): 1854-1856, doi: 10.3748/wjg.v10.113.1854, indexed in Pubmed: 15222022

8. Hard to swallow. Nature. 2007; 448(7150): 105-106, doi: 10.1038/448106a, indexed in Pubmed: 17625521.

9. Liu W, Lu L, Ma C, et al. The evolution of Traditional Chinese Medicine as a disciplinary concept and its essence throughout history. Traditional Medicine and Modern Medicine. 2018; 01(03): 171-180, doi: 10.1142/s257590001810002x

10. Stelmack R, Stalikas A. Galen and the humour theory of temperament Personality and Individual Differences. 1991; 12(3): 255-263, doi: 10.1016/0191-8869(91)90111-n

11. Goldsmith H, Buss A, Plomin R, et al. Roundtable: What is temperament? Four approaches. Child Development. 1987; 58(2): 505, doi: $10.2307 / 1130527$.

12. Javier, Hope (2014) "The Four Humours Theory," ESSAI: Vol. 12, Article 21.

13. Parker, Richard G. "The Hippocratic Humoural Theory: A Proper Philosophical and Historical Context." The Rational Argumentator 14 (2003). Web. 04 Nov. 2013.

14. Determining the Patient's Temperament: An Excursion into Seventeenth-Century Medical Semeiology. vol. 67, no. 3, 1993, pp. 417-438. JSTO. www.jstor.org/stable/44444260 (29 Aug. 2021)

15. Cybulska, Eva M. DM, DPM, MRCPsych Globus Hystericus-A Somatic Symptom of Depression? The Role of Electroconvulsive Therapy and Antidepressants, Psychosomatic Medicine: January/February 1997 Volume 59 - Issue 1 - p 67-69

16. Nasir M. Determination of Temperament with the help of Hair Thickness and Colour. Int J Tradit Med Appl. 2019; 1(1): 18-21. doi: 10.18689/ijtma-1000104

17. Jabin F. A guiding tool in Unani Tibb for maintenance and preservation of health: a review study. Afr J Tradit Complement Altern Med. 2011;8(5 Suppl):140-143. doi:10.4314/ajtcam.v8i5S.7

18. Shirbeigi L, Zarei A, Naghizadeh A, et al. The concept of temperaments in traditional Persian medicine. Trad Integr Med. ; 2(3): 143-156.

19. Muscaritoli M, Krznarić Z, Singer P, et al. Effectiveness and efficacy of nutritional therapy: A systematic review following Cochrane methodo- 
logy. Clin Nutr. 2017; 36(4): 939-957, doi: 10.1016/j.clnu.2016.06.022, indexed in Pubmed: 27448948.

20. Xie A, Huang H, Kong F. Relationship between food composition and its cold/hot properties: A statistical study. Journal of Agriculture and Food Research. 2020; 2: 100043, doi: 10.1016/j.jafr.2020.100043.

21. Koo L. The use of food to treat and prevent disease in chinese culture. Social Science \& Medicine. 1984; 18(9): 757-766, doi: 10.1016/02779536(84)90102-3.

22. Nejatbakhsh, Fatemeh et al. "Recommended foods for male infertility in Iranian traditional medicine." Iranian journal of reproductive medicine vol. 10, 6 (2012): 511-516.

23. Chen ZQ, Lu LG. [Integral syndrome differentiation, local syndrome differentiation and microcosmic syndrome differentiation --thinking on the modern TCM system of syndrome differentiation dependent treatment]. Zhongguo Zhong Xi Yi Jie He Za Zhi. 2006; 26(12): 1126-1127, indexed in Pubmed: 17205829.

24. Anderson E. 'Heating' and 'cooling' foods in Hong Kong and Taiwan. Social Science Information. 2016; 19(2): 237-268, doi: 10.1177/053901848001900203.

25. Currier R. The hot-cold syndrome and symbolic balance in Mexican and Spanish-American folk medicine. Ethnology. 1966; 5(3): 251 , doi: $10.2307 / 3772771$.

26. Dong $\mathrm{H}$, Zhang $X$. An overview of traditional Chinese medicine. Traditional Medicine in Asia. New Delhi: World Health Organization. In: Chaudhary RR, Rafei UM. ed. New Delhi: World Health Organization. Regional Office South -East Asia 2002: 116.

27. Wu Q, Liang X. Food therapy and medical diet therapy of Traditional Chinese Medicine. Clinical Nutrition Experimental. 2018; 18: 1-5, doi 10.1016/j.yclnex.2018.01.001

28. Zhao X, Tan X, Shi H, et al. Nutrition and traditional Chinese medicine (TCM): a system's theoretical perspective. Eur J Clin Nutr. 2021; 75(2): 267-273, doi: 10.1038/s41430-020-00737-w, indexed in Pubmed: 32884122

29. Maciocia G. The Foundations of Chinese Medicine. In: Maciocia G. ed. Identification of Patterns according to the Eight Principles Pages. : 179-189.

30. Jiang M, Lu C, Zhang $\mathrm{C}$, et al. Syndrome differentiation in modern research of traditional Chinese medicine. J Ethnopharmacol. 2012 140(3): 634-642, doi: 10.1016/j.jep.2012.01.033, indexed in Pubmed 22322251

31. Dashtdar M, Dashtdar MR, Dashtdar B, Kardi K, Shirazi MK. The Concept of Wind in Traditional Chinese Medicine. J Pharmacopuncture 2016;19(4):293-302. doi:10.3831/KPI.2016.19.030

32. Li R, Ma T, Gu J, et al. Imbalanced network biomarkers for traditional Chinese medicine syndrome in gastritis patients. Sci Rep. 2013; 3 1543, doi: 10.1038/srep01543, indexed in Pubmed: 23529020

33. Lao L, Xu L, Xu S. Traditional Chinese Medicine. In: Längler A, Mansky P, Seifert G. ed. Integrative Pediatric Oncology. Pediatric Oncology. Springer, Berlin 2012

34. Fitridge, Robert, and Matthew Thompson. Mechanisms of Vascular Disease: A Reference Book for Vascular Specialists. University of Adelaide Press, 2011. http://www.jstor.org/stable/10.20851/j.ctt1sq5w94.

35. Liu J, Feng W, Peng C. A song of ice and fire: Cold and Hot properties of traditional Chinese medicines. Front Pharmacol. 2020 11: 598744, doi: 10.3389/fphar.2020.598744, indexed in Pubmed: 33542688 .

36. https://www.sacredlotus.com/go/diagnosis-chinese-medicine/get/4 - pillars-pulse-images-tcm-diagnosis\#hua

37. Oh SH, Moon YJ, Oh CH. g -Aminobutyric Acid (GABA) Content of Selected Uncooked Foods. Preventive Nutrition and Food Science. 2003; 8(1): 75-78, doi: 10.3746/jfn.2003.8.1.075

38. Fisher DA, Oddie TH, Johnson DE, et al. The diagnosis of Hashimoto's thyroiditis. J Clin Endocrinol Metab. 1975; 40(5): 795-801, doi: 10.1210/jcem-40-5-795, indexed in Pubmed: 1092711

39. van Zuuren EJ, Albusta AY, Fedorowicz Z, et al. Selenium supplementation for Hashimoto's thyroiditis. Cochrane Database Syst Rev. 2013(6): CD010223, doi: 10.1002/14651858.CD010223.pub2, indexed in Pubmed: 23744563.

40. Brown KM, Arthur JR. Selenium, selenoproteins and human health: a review. Public Health Nutr. 2001; 4(2B): 593-599, doi 10.1079/phn2001143, indexed in Pubmed: 11683552.

41. Smrkolj P, Pograjc L, Hlastan-Ribič C, et al. Selenium content in selected Slovenian foodstuffs and estimated daily intakes of selenium. Food Chemistry. 2005; 90(4): 691-697, doi: 10.1016/j. foodchem.2004.04.028

42. O'Mahony SM, Clarke G, Borre YE, et al. Serotonin, tryptophan metabolism and the brain-gut-microbiome axis. Behav Brain Res. 2015 277: 32-48, doi: 10.1016/j.bbr.2014.07.027, indexed in Pubmed: 25078296
43. Young S, Leyton M. The role of serotonin in human mood and social interaction. Pharmacology Biochemistry and Behavior. 2002; 71(4): 857-865, doi: 10.1016/s0091-3057(01)00670-0

44. Inam Qu, Ikram H, Shireen $\mathrm{E}$, et al. Effects of sugar rich diet on brain serotonin, hyperphagia and anxiety in animal model of both genders. Pak J Pharm Sci. 2016; 29(3): 757-763, indexed in Pubmed: 27166525.

45. Kennedy DO. B vitamins and the brain: mechanisms, dose and efficacy--A review. Nutrients. 2016; 8(2): 68, doi: 10.3390/nu8020068, indexed in Pubmed: 26828517

46. Höglund E, Øverli $\varnothing$. Winberg S. Tryptophan metabolic pathways and brain serotonergic activity: A comparative review. Front Endocrinol (Lausanne). 2019; 10: 158, doi: 10.3389/fendo.2019.00158, indexed in Pubmed: 31024440

47. Fernstrom J. Aromatic amino acids and monoamine synthesis in the central nervous system: influence of the diet. The Journal of Nutritional Biochemistry. 1990; 1(10): 508-517, doi: 10.1016/09552863(90)90033-h.

48. Berridge KC, Kringelbach ML. Affective neuroscience of pleasure: reward in humans and animals. Psychopharmacology (Berl). 2008; 199(3): 457-480, doi: 10.1007/s00213-008-1099-6, indexed in Pubmed: 18311558

49. Blood AJ, Zatorre RJ. Intensely pleasurable responses to music correlate with activity in brain regions implicated in reward and emotion. Proc Natl Acad Sci U S A. 2001; 98(20): 11818-11823, doi: 10.1073/pnas.191355898, indexed in Pubmed: 11573015.

50. Deyoung CG. The neuromodulator of exploration: A unifying theory of the role of dopamine in personality. Front Hum Neurosci. 2013; 7 : 762, doi: 10.3389/fnhum.2013.00762, indexed in Pubmed: 24294198.

51. DeMaagd, George, and Ashok Philip. "Parkinson's Disease and Its Management: Part 1: Disease Entity, Risk Factors, Pathophysiology, Clinical Presentation, and Diagnosis." P \& T : a peer-reviewed journal for formulary management vol. 40,8 (2015): 504-32.

52. Suryawanshi SS, Kamble PP, Bapat VA, et al. Parkinsonism and Potential of Mucuna Beans. Bioethics in Medicine and Society. 2021, doi: 10.5772/intechopen.92855.

53. Krugers $\mathrm{HJ}$, Karst $\mathrm{H}$, Joels $\mathrm{M}$. Interactions between noradrenaline and corticosteroids in the brain: from electrical activity to cognitive performance. Front Cell Neurosci. 2012; 6: 15, doi: 10.3389/fncel.2012.00015, indexed in Pubmed: 22509154.

54. Moret $\mathrm{C}$, Briley M. The importance of norepinephrine in depression. Neuropsychiatr Dis Treat. 2011; 7(Suppl 1): 9-13, doi: 10.2147/NDT. S19619, indexed in Pubmed: 21750623.

55. Nehlig A, Daval JL, Debry G. Caffeine and the central nervous system: mechanisms of action, biochemical, metabolic and psychostimulant effects. Brain Res Brain Res Rev. 1992; 17(2): 139-170, doi: 10.1016/0165-0173(92)90012-b, indexed in Pubmed: 1356551.

56. Bellet S, Roman L, DeCastro O, et al. Effect of coffee ingestion on catecholamine release. Metabolism. 1969; 18(4): 288-291, doi: 10.1016/0026-0495(69)90049-3.

57. Hasselmo M, Bower J. Acetylcholine and memory. Trends in Neurosciences. 1993; 16(6): 218-222, doi: 10.1016/0166-2236(93)90159-j.

58. Corkin S. Acetylcholine, aging and Alzheimer's disease. Trends in Neurosciences. 1981; 4: 287-290, doi: 10.1016/0166-2236(81)90090-4.

59. Sagorchev P, Lukanov J, Beer AM. Investigations into the specific effects of rosemary oil at the receptor level. Phytomedicine. 2010; 17(8-9): 693-697, doi: 10.1016/j.phymed.2009.09.012, indexed in Pubmed: 20034774

60. Solomon Habtemariam, "The Therapeutic Potential of Rosemary (Rosmarinus officinalis) Diterpenes for Alzheimer's Disease", Evidence-Based Complementary and Alternative Medicine, vol. 2016, Article ID 2680409, 14 pages, 2016. https://doi.org/10.1155/2016/2680409

61. Saito M, Yoneshiro T. Capsinoids and related food ingredients activating brown fat thermogenesis and reducing body fat in humans. Curr Opin Lipidol. 2013; 24(1): 71-77, doi: 10.1097/MOL.0b013e32835a4f40, indexed in Pubmed: 23298960.

62. Westerterp KR. Diet induced thermogenesis. Nutr Metab (Lond). 2004; 1(1): 5, doi: 10.1186/1743-7075-1-5, indexed in Pubmed: 15507147.

63. Wolever TM, Jenkins $\mathrm{DJ}$, Jenkins $\mathrm{AL}$, et al. The glycemic index: methodology and clinical implications. Am J Clin Nutr. 1991; 54(5): 846-854, doi: 10.1093/ajcn/54.5.846, indexed in Pubmed: 1951155.

64. Jenkins DJ, Wolever TM, Taylor RH, et al. Glycemic index of foods: a physiological basis for carbohydrate exchange. Am J Clin Nutr. 1981; 34(3): 362-366, doi: 10.1093/ajcn/34.3.362, indexed in Pubmed: 6259925.

65. Pereira MA, Swain J, Goldfine AB, et al. Effects of a low-glycemic load diet on resting energy expenditure and heart disease risk factors during weight loss. JAMA. 2004; 292(20): 2482-2490, doi: 10.1001/jama.292.20.2482, indexed in Pubmed: 15562127. 
66. Foster-Powell K, Holt SHA, Brand-Miller JC. International table of glycemic index and glycemic load values: 2002. Am J Clin Nutr. 2002; 76(1): 5-56, doi: 10.1093/ajcn/76.1.5, indexed in Pubmed: 12081815.

67. Blaak EE, Antoine JM, Benton D, et al. Impact of postprandial glycaemia on health and prevention of disease. Obes Rev. 2012 13(10): 923-984, doi: 10.1111/j.1467-789X.2012.01011.x, indexed in Pubmed: 22780564

68. Marathe CS, Rayner CK, Jones KL, et al. Relationships between gastric emptying, postprandial glycemia, and incretin hormones. Dia- betes Care. 2013; 36(5): 1396-1405, doi: 10.2337/dc12-1609, indexed in Pubmed: 23613599

69. Ludy MJ, Mattes RD. Comparison of sensory, physiological personality, and cultural attributes in regular spicy food users and non-users. Appetite. 2012; 58(1): 19-27, doi: 10.1016/j.appet.2011.09.018, indexed in Pubmed: 21986186.

70. Barceloux DG. Pepper and capsaicin (Capsicum and Piper species) Dis Mon. 2009; 55(6): 380-390, doi: 10.1016/j.disamonth.2009.03.008, indexed in Pubmed: 19446682 